\title{
Stress monitoring of long-span steel truss during construction stage in Hangzhou International Expo Center
}

\author{
Jindi $\mathrm{Lin}^{1, *}$, Yongbin $\mathrm{Wei}^{1}$, and Maowei Qiao ${ }^{1}$ \\ ${ }^{1}$ China State Construction Engineering Corporation, Beijing, China
}

\begin{abstract}
According to the requirement of building function, the large-span steel structures are constantly appearing in recent years. It is necessary to establish a set of feasible methods for health monitoring of longspan steel structures. This paper introduces the structural health monitoring of large-span steel structure in Construction Stage, including the method of Structural simulation, the wireless monitoring system of largespan steel structure, the installation method of sensors, the judgment method of structural safety and the maintenance of monitoring system. Taking Hangzhou International Expo Center as an example, all construction steps of the main large-span steel structure were simulated by the finite element analysis software. Through the structure of simulation calculation, the key members of the structure were found out, and the monitoring scheme was determined and carried out. In order to get the accurate stress data during the implementation of the monitoring scheme, this paper introduced some attentive details of sensor installation. The limitation of the key steel elements was obtained according to the related norms, and it provided the judgment for the safe of structure. After the smooth construction of the project, we could find that the stress monitoring system meted the monitoring requirement during the construction stage, and the results were an important evaluation index for the structure. The research methods used in this paper could be seen as useful reference for construction of similar projects. Stress monitoring of long-span steel struss during construction stage in Hangzhou International Expo Center.
\end{abstract}

\section{Introduction}

In recent years, with the rapid improvement of civil engineering technology, various spatial structures are developing towards large-scale and complex direction. The construction of large-span spatial structures has become an important symbol to measure the technical level of a country's construction ${ }^{[1-6]}$. A large number of special buildings have emerged in the world, such as China's National Stadium, the new CCTV site, Dubai's Dance Towers, Singapore's Durian Shell Theatre and so on, which have brought great visual impact to people.

After we see these amazing architectural appearances, we should also recognize the construction complexity is hidden behind the large complex steel structures. At present, due to the hoisting and welding of large components, accidents occur frequently in the process of steel structure construction, and many construction personnel are in distress every year. According to the records, 59 of the nearly 120 steel structure accidents occurred in the production or installation stage in the world. The probability of accidents in this stage is as high as $49.2 \%{ }^{[7]}$. The main reasons for this situation are that the construction conditions are not fully considered in design, the local construction load is far greater than the design load, the site construction quality cannot fully meet the design requirements, and the construction units lack experience in complex steel structure construction.
So it need to require relevant units to monitor the construction process of complex steel structures. Through the monitoring in the construction process, it can provide the technical basis for site decision-making, and it also can provide the original data for the monitoring in the subsequent operation stage.

The Hangzhou International Expo Center project has a total construction area of about 850,000 square meters, a total weight of 140,000 tons of steel structure and a total number of 62,000 steel components, as indicated in figure 1 below.

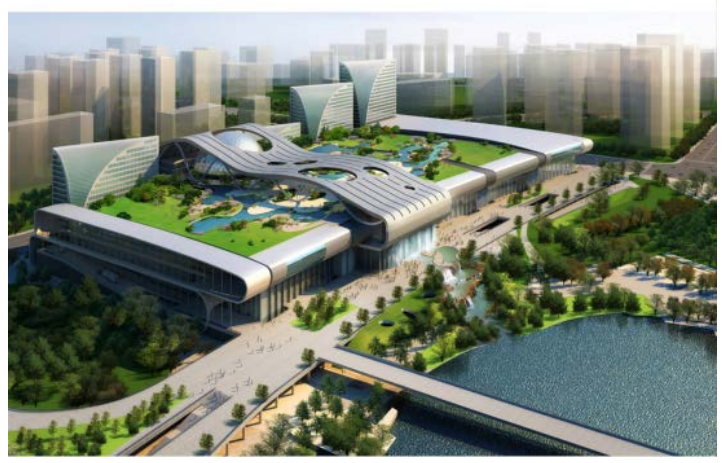

Fig 1. Design sketch of structure.

The Exhibition Center is an important part of this structure. The Exhibition Centre is a three-story steel frame structure, which composed of concrete filled steel 
tubular columns and steel truss beams, as indicated in figure 2 below.

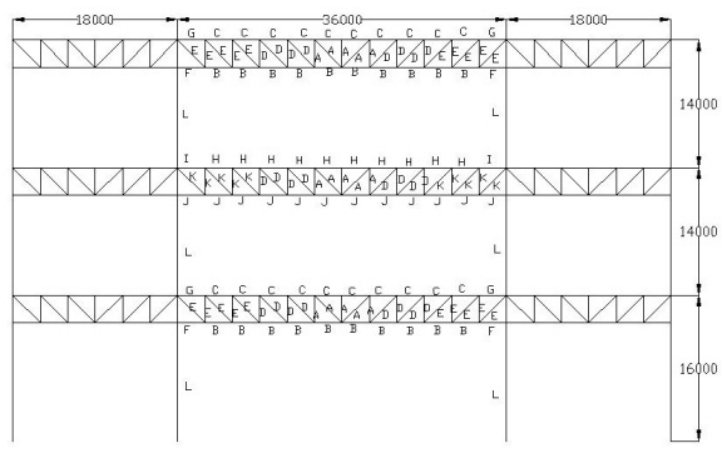

Fig 2. Three-story steel frame structure.

The maximum span is 36 meters and the spacing between frames is 27meters. In this paper, the steel frame of exhibition is selected for stress analysis and monitoring in the construction stage. The columns in the frame are concrete filled steel tubular columns, the concrete is C60, and the steel is Q345. The sectional dimensions of each member of the frame structure are shown in the table 1 below.

Table 1. Section size of component.

\begin{tabular}{ccc}
\hline Component & Section form & Section size $(\mathrm{mm})$ \\
\hline A & H & $200 * 204 * 12 * 12$ \\
B & H & $400 * 500 * 35 * 40$ \\
C & H & $400 * 400 * 25 * 30$ \\
D & H & $344 * 348 * 10 * 16$ \\
E & H & $400 * 400 * 30 * 30$ \\
F & H & $400 * 500 * 40 * 40$ \\
G & H & $400 * 400 * 35 * 35$ \\
H & H & $400 * 400 * 20 * 25$ \\
I & H & $400 * 400 * 30 * 30$ \\
J & H & $400 * 500 * 30 * 40$ \\
K & H & $400 * 400 * 25 * 25$ \\
L & TUBE & $1600 * 30$ \\
\hline
\end{tabular}

\section{Figures and tables}

\subsection{Modeling}

ANSYS is used to simulate and analyse the structural changes in the construction process. BEAM188 is used to simulate the steel truss components. LINK10 is used to simulate the temporary support in the middle span. The finite element model is shown in Figure 3.

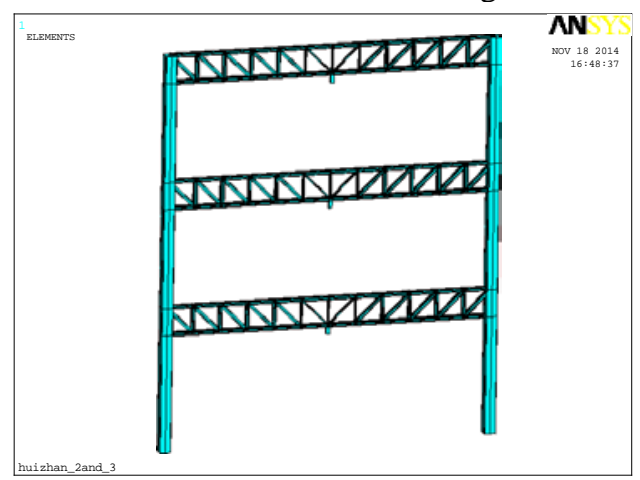

Fig 3. Structural simulation model.

\subsection{Simulation for structure in construction}

This paper simulates the whole construction process of three-storey steel truss. The steps are as follows:

1)the first-storey steel truss was temporarily supported in the middle of the span;

2)the second-storey steel truss was temporarily supported in the middle of the span;

3)the third-storey steel truss was temporarily supported in the middle of the span;

4)the third temporary support was removed;

5)the second temporary support was removed;

6)the first temporary support was removed.

\section{The Wireless monitoring of stress}

\subsection{Wireless monitoring system}

The wireless monitoring system was composed of sensor system, real-time acquisition system, real-time data transmission system, real-time data processing system, data storage and backup system, intelligent diagnosis and warning system, and so on. The sensor system was consist of strain sensors and temperature sensors, which is used to monitor the response of the structure caused by construction and climate conditions.

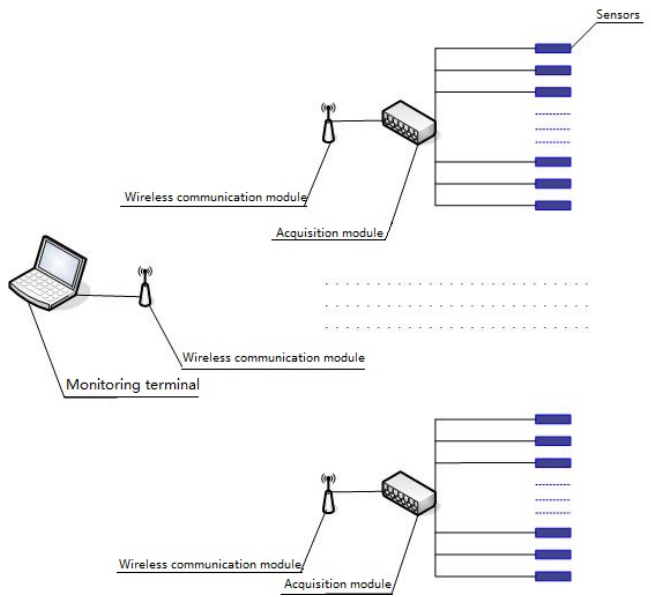

Fig 4. Monitoring system

Due to the complexity of the construction site, the monitoring equipment adopts the wireless transmission mode, which is convenient to install the monitoring system in the construction site. The system also has data stability, high precision, reliability and durability, which can meet the requirements of long-term construction monitoring.

\subsection{Plans of monitoring points}

The strain measurement points should be located in the areas, where the strain changes obviously and the strain is complex. According to the results of ANSYS simulation calculation, the monitoring scheme of this structure is shown in Figure 5. There are 24monitoring points, each monitoring point is used to monitor strain and temperature. In this monitoring scheme, data 
transmission of the system should be as centralized as possible, and obey the principle of block centralization ${ }^{[8]}$.

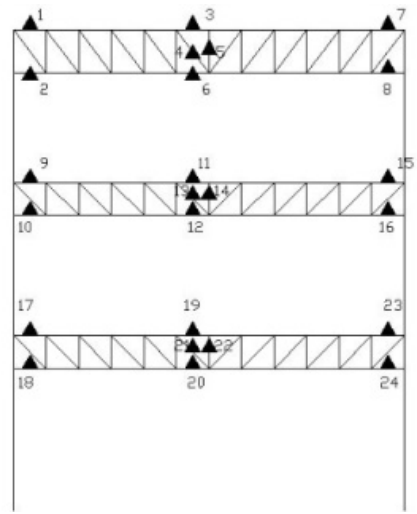

Fig 5. Three-story steel frame structure.

In order to avoid the inaccuracy of monitoring data caused by sensor installation, and then cause structural safety problems, the following details should be paid attention to in the process of sensor installation ${ }^{[9-11]}$ :

(1) The axis of vibrating wire sensor installed is parallel to the measurement direction;

(2) The sensor is firmly installed on the surface of steel structure;

(3) The sensor needs to be corrected for temperature compensation.

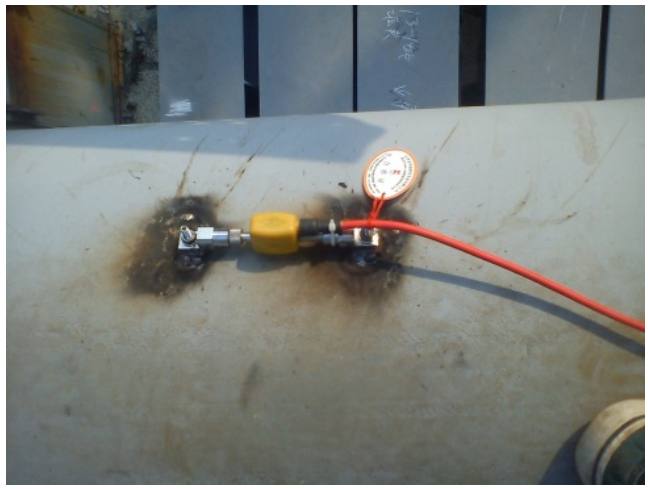

Fig 6. Sensor installation.

\subsection{The method of choosing initial stress value}

The initial monitoring state, which was defined as zero stress state, was that the steel truss had been assembled. In fact, the steel components had stress due to their own weight at this moment, so it is necessary to simulate the working conditions of the structure at the initial state. In subsequent monitoring, the measured stress values were accumulated as the final structural strain values.

According to the implementation of the construction, the initial strain values of the steel components were obtained by finite element simulation analysis, as shown in Table 2.

Table 2. Initial stress values (Mpa).

\begin{tabular}{cc}
\hline $\begin{array}{c}\text { Monitoring } \\
\text { point }\end{array}$ & $\begin{array}{c}\text { Initial stress } \\
\text { value }\end{array}$ \\
\hline 1,7 & 0.01 \\
2,8 & -0.006 \\
\hline
\end{tabular}

\begin{tabular}{cc}
\hline 3 & 0.024 \\
4 & -0.108 \\
5 & -0.035 \\
6 & -0.0097 \\
9,15 & 0.0018 \\
10,16 & -0.011 \\
11 & 0.029 \\
12 & -0.007 \\
13 & -0.094 \\
14 & -0.0287 \\
17,23 & 0.0019 \\
18,24 & -0.01 \\
19 & 0.0204 \\
20 & -0.0034 \\
21 & -0.0948 \\
22 & -0.0327 \\
\hline
\end{tabular}

\subsection{Determination of upper and lower limits of stress}

According to the relevant provisions in the code for design of steel structure, the following equations ${ }^{[12]}$ were used to find the upper and lower limit values of stress, which determined by the strength of steel and the stability requirement of steel members. And 70\% times of the upper and lower limit was taken as the early waring value of stress monitoring.

$$
\begin{aligned}
& \mathrm{N} / \mathrm{An} \leqslant \mathrm{f} \\
& \mathrm{N} / \phi \mathrm{An} \leqslant \mathrm{f}
\end{aligned}
$$

The stress limits of each steel member are shown in the Table 3.

Table 3. Upper and lower limit value (Mpa).

\begin{tabular}{ccc}
\hline Steel member & $\begin{array}{c}\text { Upper limit } \\
\text { value }\end{array}$ & $\begin{array}{c}\text { Lower limit } \\
\text { value }\end{array}$ \\
\hline $1,7,17,23$ & -287.5 & 295 \\
$2,8,18,24$ & -262.1 & 265 \\
9,15 & -287.6 & 295 \\
3,19 & -287.9 & 295 \\
6,20 & -292.2 & 295 \\
$10,16,12$ & -292.1 & 295 \\
$4,5,13,14,21,22$ & -269.1 & 310 \\
11 & -288.4 & 295 \\
\hline
\end{tabular}

\subsection{Monitoring results}

According to the relevant provisions in the code for design of steel structure, the following equations ${ }^{[12]}$ were used to find the upper and lower limit values of stress, which determined by the strength of steel and the stability requirement of steel members. And $70 \%$ times of the upper and lower limit was taken as the early waring value of stress monitoring.

In order to illustrate the monitoring effect, the stress changes of key members are analysed. The monitoring point 11 was selected for analysis in this paper. The strain variation was shown in the Figure 7, and the temperature variations were shown in the Figure 8. We can find that the strain of the member increases gradually with the increase of load during construction. And each monitoring points were within the warning value during the whole construction stage. Meanwhile, 
the temperature change of air directly affects the stress value of the steel structure under the condition of constant external load. When the temperature difference is large, the structural stress cannot be ignored.

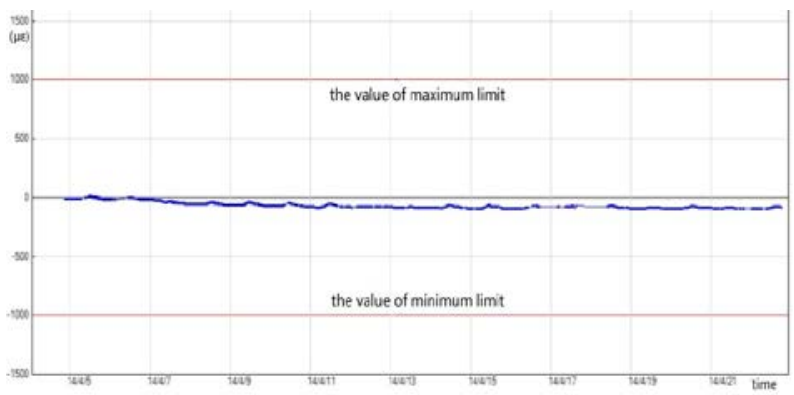

Fig7. Strain variation of point 11.

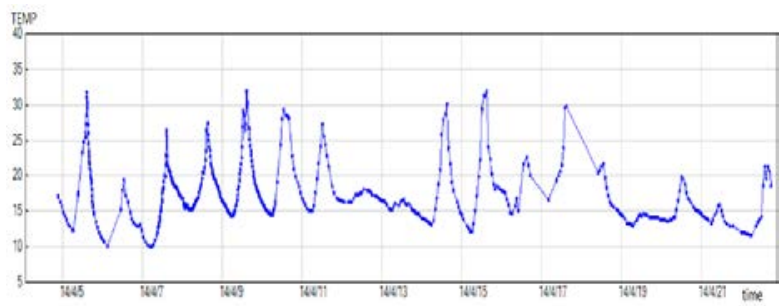

Fig8. Temperature variation of point 11.

The other monitoring points in this monitoring reflect the above phenomena, and it also do not exceed the early warning value. The construction monitoring can complete the monitoring task well in the process of steel structure construction.

\section{Conclusion}

In this paper, the finite element simulation analysis and monitoring of the steel structure of Hangzhou International Expo Centre during construction loading process. We can find the following conclusions.

(1)The monitoring system can complete the monitoring work in the complex construction site. And the system has the characteristics of good reliability, strong anti-interference ability and high sensitivity.

(2)According to the simulation results, the key positions of the members are selected for the whole construction monitoring in the complex steel structures.
Through monitoring, we can know the stress state of the structure in real time, and we can ensure the safety of the whole structure.

(3)Temperature should be taken into account in the construction of complex steel structures. In the construction with large difference between day and night, it is necessary to consider the response of temperature stress.

(4)According to the results of simulation analysis and measurement, the selection of key points is effective in the construction process, and the method of judging structural safety is feasible. All of our work can provide reference for monitoring similar projects in the future.

\section{References}

1. Qian, J R., Zhang, W J.and Zhao, Z Z. China Civil Engineering Journal 10 13-20(2009).

2. Lei, J J., Liu, Y F., Duan, X J.. Engineering Mechanics.35 203-211(2018).

3. Zhang, J G., Zhao, Z F., Gao, Q B.. Steel Construction. 33 120-125(2018).

4. Zhao, Y S., Guo, M., Duan, X S.. Research \& Explore. 32 3-7(2014).

5. Wang, X L., Rong, Z H., Yang, B X.. Journal of Architecture and Civil Engineering. 34 18-25(2017).

6. Cao, P Z., Li, D., Fu, X Z., Wu, W P.. Progress in Steel Building Sturctures. 18 69-74(2016).

7. Wang, X B. Zhejiang University, Hangzhou Health monitoring application and research in construction process of the steel structure 2010 (2010)

8. Lin, J D. and Wei, Y B. Construction \&design for project 12 121-123(2010)

9. Wang, Y B., Zhao, R D., Chen, L.. Journal of Architecture and Civil Engineering. 34 68-75(2017).

10. Shi, K H., Chang, L., Wang, Y P.. Research \& Explore. 34 31-35(2016).

11. Wang, Y., Li, Y P., Zhang, B.. Journal of Taiyuan University of Technology. 51 206-210(2020).

12. Code for Design of Steel Structures $\boldsymbol{G B}$ 500172003(2003) 